\title{
Trypanosoma cruzi: Seroprevalence Detection in Suburban Population of Santiago de Querétaro (Mexico)
}

\author{
Ángeles López-Céspedes, ${ }^{1}$ Elena Villagrán, ${ }^{2}$ Kervin Briceño Álvarez, ${ }^{1}$ \\ José Antonio de Diego, ${ }^{3}$ Hebert Luís Hernández-Montiel, ${ }^{2}$ Carlos Saldaña, ${ }^{2}$ \\ Manuel Sānchez-Moreno, ${ }^{1}$ and Clotilde Marín ${ }^{1}$ \\ ${ }^{1}$ Departamento de Parasitología, Facultad de Ciencias, Universidad de Granada, Severo Ochoa s/n, 18071 Granada, Spain \\ ${ }^{2}$ Departamento de Investigación Biomédica, Facultad de Medicina, UAQ, 76050 Santiago de Queretaro, QRO, Mexico \\ ${ }^{3}$ Unidad de Parasitología y Medicina Tropical, Departamento de Medicina Preventiva y Salud Pública, Facultad de Medicina, \\ UAM, 28049 Madrid, Spain
}

Correspondence should be addressed to Clotilde Marín, cmaris@ugr.es

Received 8 November 2011; Accepted 13 December 2011

Academic Editor: Yoshihisa Hashiguchi

Copyright (C) 2012 Ángeles López-Céspedes et al. This is an open access article distributed under the Creative Commons Attribution License, which permits unrestricted use, distribution, and reproduction in any medium, provided the original work is properly cited.

\begin{abstract}
Objectives. To evaluate the potential of iron-oxide dismutase excreted (SODeCRU) by T. cruzi as the antigen fraction in the serodiagnosis of Chagas disease and compile new epidemiological data on the seroprevalence of this disease in the suburban population of the city of Santiago de Querétaro (Mexico). Design and Methods. 258 human sera were analyzed by the techniques of ELISA and Western blot and using the homogenate and the SODeCRU. Results. A total of 31 sera were positive against ELISA/SODeCRU (12.4\%), while 30 sera proved positive by WB/SODeCRU (11.6\%). The comparison between the technique of ELISA and WB showed a sensitivity of $93 \%$, and a specificity of $99 \%$. The positive predictive value was $93 \%$ and the negative predictive value was $99 \%$, with a Kappa $(\kappa)$ value of 1 . Conclusions. These preliminary data reveal the degree of infection of nonrural areas of Mexico and demonstrated that SODeCRU is an antigen useful to diagnose Chagas disease.
\end{abstract}

\section{Introduction}

Chagas disease, or American trypanosomiasis, is an infectious tropical disease caused by the blood flagellate Trypanosoma cruzi, which in its natural form is transmitted by Hemipteran vectors colloquially called "vinchucas" in Mexico and certain areas of South America. In addition, other forms of infection are known: blood transfusions, organ transplants, oral transmission, and congenital transmission. The first phase of the infection (acute phase) has clinical symptoms such as fever, discomfort, and cephalea and thus can be confused with the flu. These symptoms remit spontaneously, when the parasite passes to the mononuclear phagocytic system, nervous system (autonomic and myoenteric plexus), and the myocardium. Thereafter, years or even decades may pass without clinical manifestations (indeterminate phase). This phase can be diagnosed only by serological diagnosis. When the chronic phase appears (anatomical alterations, megaesophagus, megacolon, and especially myocardiopathy), the disease has no cure and most patients die a sudden death without the causes being known [1].

The Pan American Health Organization estimates that there are currently 7.7 million people infected by $T$. cruzi in 21 endemic countries, with the appearance of 41,200 cases per year, and 14,400 children are born annually with congenital Chagas disease. The countries most affected are Bolivia (6.8\% of the cases reported), Argentina (4.1\%), El Salvador (3.4\%), Honduras (3.1\%), Paraguay (2.5\%), Guatemala (2\%), Ecuador (1.7\%), French Guyana, Guyana, and Surinam (1.2\%), Venezuela (1.2\%), Nicaragua $(1.1 \%)$, Brazil (1\%), and Mexico (1.3\%) [2].

The enormous progress made in the control of Chagas disease in the last few decades indicates clearly that the 
obstacles against the complete elimination of transmission of T. cruzi to the human are mainly economic and political. In this context, there are additional noteworthy advances such as the more detailed understanding of the pathogen of Chagas disease, genetic analyses, new diagnostic techniques, and advances in the development of vaccines [3].

The diagnosis of Chagas disease depends on the phase of the disease. In the acute phase, the diagnosis is made by direct examination of the parasite in body fluids. In this acute or reactivation [4] phase, when the parasitaemia is high, the live parasite can be easily detected with its rapid movements. Other techniques used for the direct observation of the parasite include blood or droplet smear and exodiagnosis. These methods present, respectively, a sensitivity of $60-70 \%$ [5]. Despite being the most commonly used for their low costs, these techniques do not present high sensitivity and thus new inexpensive, quick methods are being sought $[6,7]$.

In the detection of Chagas disease, the PCR technique can be used, although in addition to the high cost and not being available in most of the laboratories of the endemic areas, it has highly variable sensitivity $(45 \%-96.5 \%)$ and can amplify nonspecific products, giving false positives $[5,8,9]$.

For all these reasons, the serological tests could represent the effective diagnosis for their sensitivity and relatively low cost. These are divided into two groups: conventional tests, which use the total parasite extract as the antigen, or soluble extract of an antigen complex; nonconventional tests, which usually use recombinant antigens or synthetic peptides [10]. Serological diagnosis gives different results according to the type of antigen used, the phase of the disease, and the type of immunoglobulins (IgG or IgM). The choice of the antigen is important for good results [11].

Many studies made to define a specific T. cruzi antigen that would increase the specificity of the serodiagnosis. One possibility is the iron-superoxide dismutase excreted by $T$. cruzi (Fe-SODeCRU or SODeCRU), which, in previous studies, has proven strongly immunogenic and highly specific, becoming useful to diagnose this disease $[12,13]$.

A prime objective of this study is to evaluate the potential of Fe-SODe of T. cruzi as the antigen fraction, in the diagnosis of Chagas disease, through the analysis of 258 human sera from the suburban area of the city of Santiago de Querétaro (Mexico), by the ELISA and Western Blot techniques. The standardization of the ELISA and Western blot techniques for screening Chagas patients, using the homogenate fraction and the SODeCRU as the antigen fraction, enables us to work towards the second objective: to compile epidemiological data on the seroprevalence of Chagas disease in suburban communities of the city of Santiago de Querétaro, which until now has not been studied.

\section{Material and Methods}

2.1. Parasites and Culture. Epimastigotes of T. cruzi (MHOM/ME/2006/H-4) were grown in axenic medium Trypanosomes Liquid Medium (MTL, Gibco) supplemented with $10 \%$ heat-inactivated foetal bovine serum at $28^{\circ} \mathrm{C}$ in Falcon flasks [14].

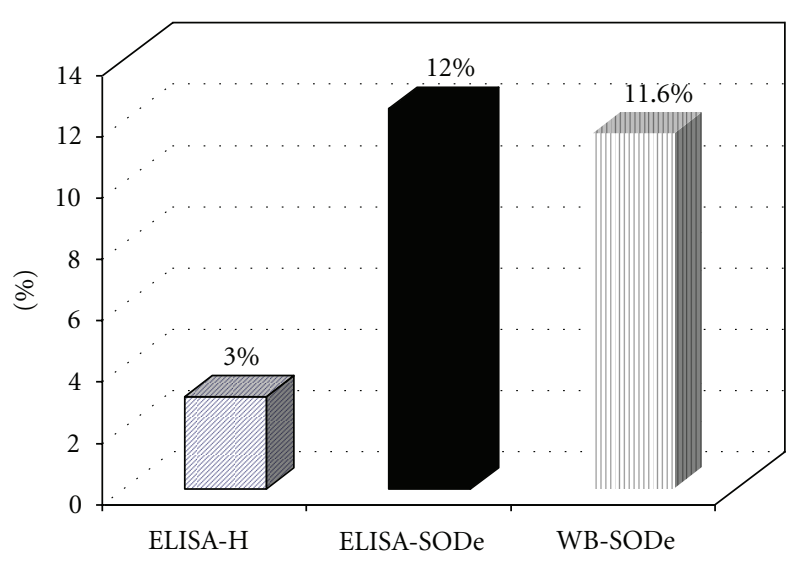

FIGURE 1: Seroprevalence of Chagas disease in suburban population of Querétaro city (Mexico) by ELISA (Homogenate and SODe) and Western Blot SODe tests.

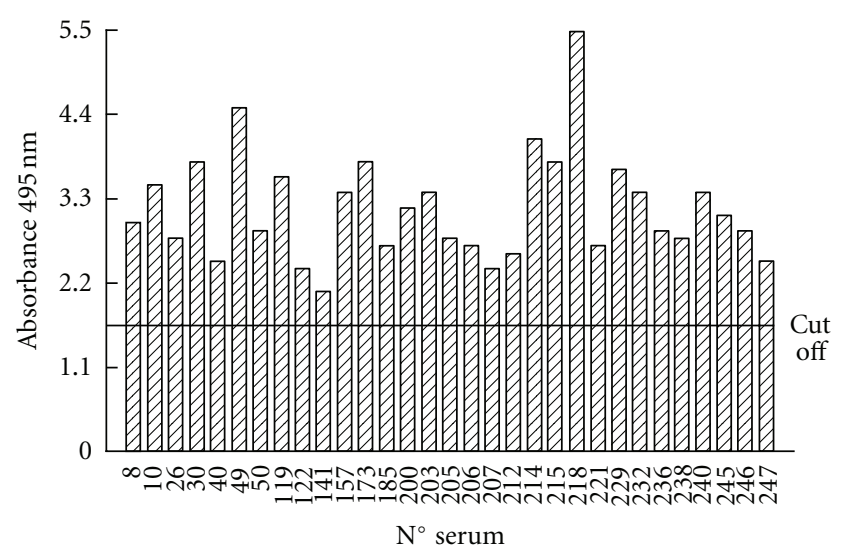

FIGURE 2: Results of the assay of 258 serum samples from human, collected in the suburban population of Querétaro city (Mexico) by enzyme-linked immunosorbent assay using the Fe-SODe by $T$. cruzi, as antigen at a dilution of $1 / 100$. The mean and standard deviation of the optical densities of the control sera were used to calculate the cut-off value (mean $\times 3$ _standard deviation).

2.2. Donor Selection and Study Design. The sample was taken in the suburban areas (communities) of the city of Santiago Querétao (in the state of Querétaro, Mexico). The city is located at an average altitude of $1,820 \mathrm{~m}$ a.s.l., at $20^{\circ} 35^{\prime}$ $34.8^{\prime \prime}$ of latitude north and $100^{\circ} 23^{\prime} 31.6^{\prime \prime}$ of longitude west, a $221 \mathrm{~km}$ to the north-northwest of Mexico City. According to a June 2010 census (XIII Censo de Población y Vivienda), the population of the city centre was 626,517 , with 801,833 inhabitants in the greater city, and 1,096,978 in the entire metropolitan zone, making it the 10th largest city in Mexico.

The average annual temperature is $26.4^{\circ} \mathrm{C}$, the maximum average temperature being around $37^{\circ} \mathrm{C}$, in May, and the minimum temperature is $11.5^{\circ} \mathrm{C}$, in January. The mean annual precipitation of the state is 638.3 , with rains in summer from June to October (National Weather Service, http://smn.cna.gob.mx/).

A total of 258 human sera were evaluated (collected from February to October 2010), which were not grouped 


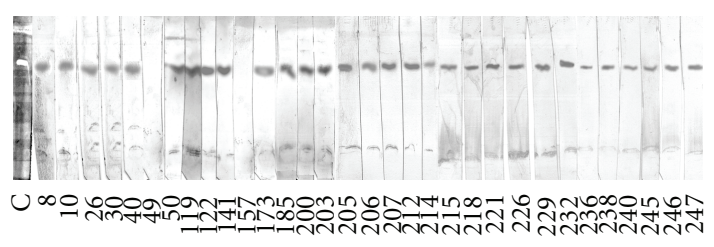

FIGURE 3: Immunoblot of the positive sera of the 258 human sera collected in the suburban population of Querétaro city (Mexico) against the SODe antigen from T. cruzi epimastigotes at a serum dilution of 1/100. Line C: SODe activity in isoelectrofocus and staining following the technique of Beyer and Fridovich [15].

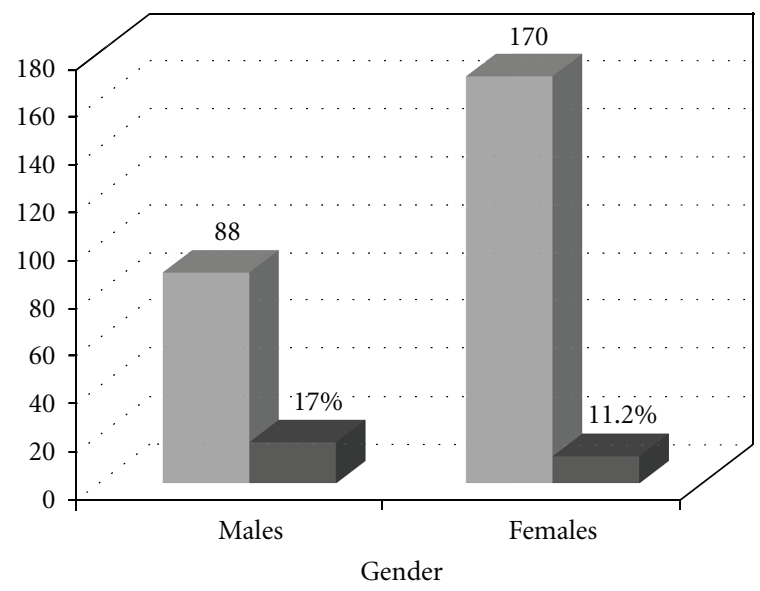

FIGURE 4: Seroprevalence of Chagas disease distributed by genders compared with the total of sera. Total samples analysed 258 (88 males and 170 females).

under any classification category (only numbered from 1 to 258). The sera were considered only as belonging to suburban communities pertaining to the city of Santiago de Querétaro, where the dwellings built under conditions of poverty occupy areas of hills and grazing areas, and domestic animals were present. The following analytic data were recorded: pathological alterations, age, sex, and place of origin of the patients (Table 1). The donors signed an informed consent form, and the study design was approved by the Ethics Committee for Research of the University of Granada (Spain).

A sample of $5 \mathrm{~mL}$ of whole blood was drawn from the ulnar vein of each human into assay tubes (Vacuttainer, Beckton-Dickinson, USA) and kept at $4^{\circ} \mathrm{C}$. The negative control sera (20, healthy or asymptomatic human, who had never received a blood transfusion, nor organ transplant, nor had lived in a country endemic of Chagas disease) were obtained by the health services in Granada (Spain), which were not reactive to the Western Blot techniques.

2.3. Total Extract of the Parasite (Fraction H). The parasite culture (in the exponential growth phase) was concentrated by centrifugation at $1500 \mathrm{rpm}$ for $10 \mathrm{~min}$. The pellet of the cells was washed twice and resuspended in ice-cold STE buffer $(0.25 \mathrm{M}$ sucrose, $25 \mathrm{mM}$ Tris- $\mathrm{HCl}, 1 \mathrm{mM}$ EDTA, pH

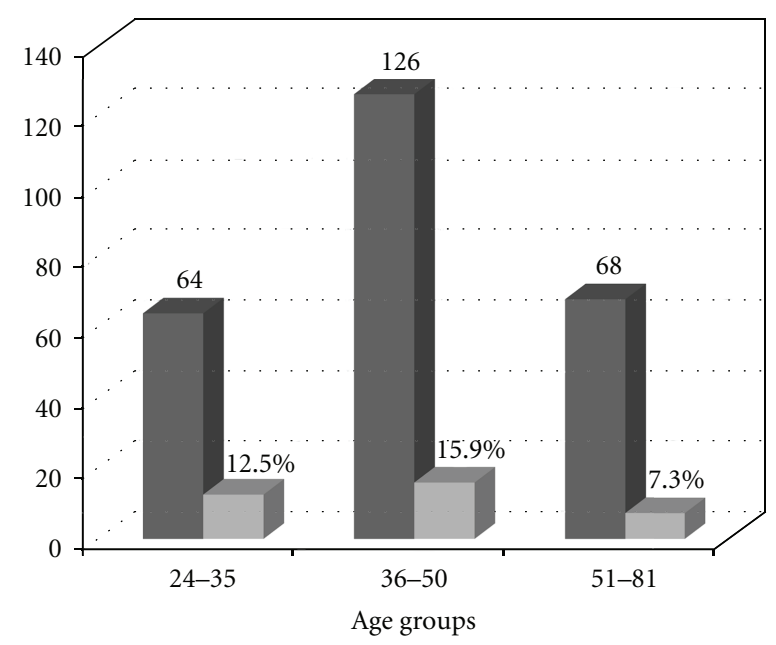

Figure 5: Seroprevalence of Chagas disease distributed by age groups compared with the total of sera. For range from 24 to 35, $n=64$, range from 36 to $50, n=126$, and range from 51 to 81 , $n=68$.

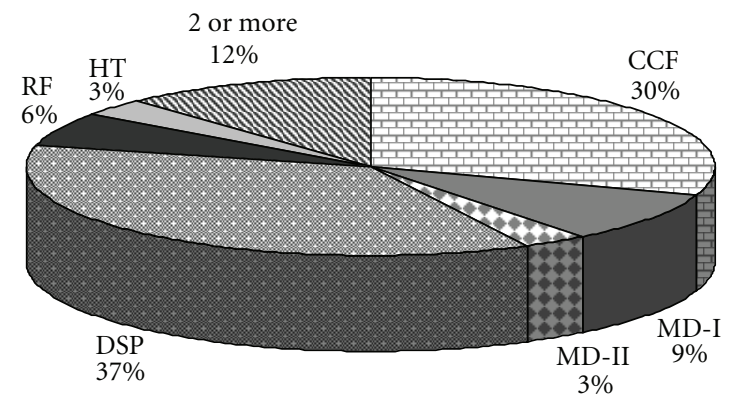

Figure 6: Associated pathologies in positive patients of Chagas Disease. CCF: chronic cardiac failure; RF: renal failure; HT: hyperthyroidism; DSP: dyslipidemia; MD-I: mellitus diabetes type 1; MD-II: mellitus diabetes type 2; 2 or more represents the combination of two or more of these pathologies.

7.8) (Buffer 1). Afterwards, the pellet was suspended (0.5$0.6 \mathrm{~g}$ wet weight $\mathrm{mL}^{-1}$ ) in $3 \mathrm{~mL}$ of buffer 1 and disrupted by three cycles of sonic disintegration, $30 \mathrm{~s}$ each at $60 \mathrm{~V}$. The sonicated homogenate was centrifuged at $1500 \mathrm{rpm}$ for $10 \mathrm{~min}$ at $4^{\circ} \mathrm{C}$, and the pellet was washed three times with buffer 1 for a total supernatant fraction of $9 \mathrm{~mL}$. This fraction was centrifuged $\left(2500 \mathrm{rpm}\right.$ for $10 \mathrm{~min}$ at $\left.4^{\circ} \mathrm{C}\right)$, and the supernatant (fraction $\mathrm{H}$ ) was collected [12].

\subsection{Extraction and Purification of the SOD Excreted (SODe-} $C R U)$. Parasite forms in the exponential growth phase, obtained as described above, were concentrated by centrifugation at $1500 \mathrm{rpm}$ for $10 \mathrm{~min}$, the pellet of the cells was washed twice in MTL medium without serum, and the number of cells was counted in a haemocytometric chamber and distributed into aliquots of $5 \times 10^{9}$ parasites $/ \mathrm{mL}$. Afterwards, the parasites were again grown in MTL medium without serum for $24 \mathrm{~h}$; the supernatant was collected by centrifugation at $1500 \mathrm{rpm}$ for $10 \mathrm{~min}$ and then passed 
TABLE 1: Relationship of positive sera of human from Queretaro (Mexico) by ELISA and Western Blot against different antigen fractions of Trypanosoma cruzi associated with age, gender, and pathology.

\begin{tabular}{|c|c|c|c|c|c|c|}
\hline Sera & $\begin{array}{c}\text { ELISA } \\
\mathrm{HOG}^{(\mathrm{a})}\end{array}$ & $\begin{array}{c}\text { ELISA } \\
\text { SODe }^{(\mathrm{b})}\end{array}$ & $\begin{array}{c}\text { WB } \\
\text { SODe }^{(\mathrm{c})}\end{array}$ & Age & Gender & Pathology $(\mathrm{d})$ \\
\hline 8 & - & + & + & 53 & M & DM-I \\
\hline 10 & - & + & + & 40 & $\mathrm{~F}$ & HPG \\
\hline 26 & - & + & + & 53 & $\mathrm{~F}$ & DM-I + ICC \\
\hline 30 & - & + & + & 43 & M & CCF \\
\hline 40 & - & + & + & 32 & $\mathrm{~F}$ & HPC \\
\hline 49 & + & + & - & 43 & M & $\mathrm{ICC}+\mathrm{DSP}$ \\
\hline 50 & + & + & + & 39 & $\mathrm{~F}$ & CCF \\
\hline 119 & + & + & + & 45 & $\mathrm{~F}$ & HPG \\
\hline 122 & + & + & + & 35 & M & DM-II \\
\hline 133 & - & - & + & 80 & M & DM-II \\
\hline 141 & - & + & + & 27 & $\mathrm{~F}$ & $\mathrm{RF}$ \\
\hline 157 & - & + & - & 37 & $\mathrm{~F}$ & DSP \\
\hline 173 & - & + & - & 67 & M & DSP \\
\hline 185 & + & + & + & 33 & $\mathrm{~F}$ & DSP \\
\hline 200 & - & + & + & 50 & $\mathrm{~F}$ & DSP \\
\hline 203 & + & + & + & 48 & M & HPC \\
\hline 204 & + & - & - & 54 & $\mathrm{~F}$ & DM-I + DSP \\
\hline 205 & - & + & + & 43 & $\mathrm{~F}$ & CCF \\
\hline 206 & - & + & + & 27 & $\mathrm{~F}$ & DSP \\
\hline 207 & - & + & + & 29 & $\mathrm{~F}$ & CCF \\
\hline 212 & - & + & + & 48 & M & HT \\
\hline 214 & - & + & + & 35 & M & DSP \\
\hline 215 & - & + & + & 27 & M & DSP \\
\hline 218 & - & + & + & 39 & M & DM-I \\
\hline 221 & - & + & + & 40 & $\mathrm{~F}$ & HPC \\
\hline 226 & - & - & + & 37 & M & CCF \\
\hline 229 & - & + & + & 51 & $\mathrm{~F}$ & CCF \\
\hline 232 & - & + & + & 42 & $\mathrm{~F}$ & DM-I \\
\hline 236 & - & + & + & 44 & M & HPG \\
\hline 238 & - & + & + & 49 & M & $\mathrm{CCF}$ \\
\hline 240 & + & + & + & 43 & $\mathrm{M}$ & CCF \\
\hline 245 & - & + & + & 43 & $\mathrm{~F}$ & $\mathrm{CCF}$ \\
\hline 246 & - & + & + & 44 & $\mathrm{~F}$ & CCF \\
\hline 247 & - & + & + & 43 & $\mathrm{~F}$ & $\mathrm{RF}$ \\
\hline
\end{tabular}

(a) ELISA-HOG: Enzyme-Linked Immunosorbent Assay (ELISA) using total parasite extract (HOG) of T. cruzi as antigen fraction.

(b) ELISA-SODe: Enzyme-Linked Immunosorbent Assay (ELISA) using excreted superoxide dismutase (SODe) by epimastigotes of T. cruzi as antigen fraction. (c) WB-SODe: Western Blot (WB) using excreted superoxide dismutase (SODe) by epimastigotes of T. cruzi as antigen fraction.

(d) Pathology abreviations: MD-I: mellitus diabetes type 1; MD-II: mellitus diabetes type 2; HPG: hipertrigliceridemia; CCF: chronic cardiac failure; HPC: hypercholesterolemia; DSP: dyslipidemia; RF: renal failure; HT: hyperthyroidism.

through a filter of $0.45-\mu \mathrm{m}$ pore size, and solid ammonium sulphate added. The protein fraction, which precipitated at between 35 and $85 \%$ salt concentration, was centrifuged (9000 rpm for $20 \mathrm{~min}$ at $4^{\circ} \mathrm{C}$ ), redissolved in $2.5 \mathrm{~mL}$ of $20 \mathrm{mM}$ potassium phosphate buffer ( $\mathrm{pH} 7.8$ ) containing $1 \mathrm{mM}$ EDTA (Buffer 2), and dialysed in a Sephadex G25 column (Pharmacia, PD 10), previously balanced with Buffer 2, bringing it to a final volume of $2.5 \mathrm{~mL}$ (fraction SODeCRU) [16].
Both fractions, $\mathrm{H}$ and SODeCRU, were used as antigen fractions in the ELISA and Western Blot assays. The protein content was determined using the Bio-Rad test, based on the Bradford method (Sigma Immunochemical, St. Louis), with bovine serum albumin as a standard [16].

2.5. Serological Assay (ELISA). For the ELISA assay, $\mathrm{H}$ and SODeCRU of the parasites, cultured and processed as 
TABle 2: Evaluation of the reliability to detect Trypanosoma cruzi antibodies, using ELISA technique with SODeCRU antigen, in 258 human sera from the suburban population in the city of Santiago de Querétaro (Mexico). The values given are estimated with Western Blot as the comparator.

\begin{tabular}{lc}
\hline & ELISA-SODeCRU \\
\hline Sensitivity & $93 \%$ \\
Specificity & $99 \%$ \\
Positive predictive value & $93 \%$ \\
Negative predictive value & $99 \%$ \\
Kappa index & 1 \\
\hline
\end{tabular}

described above, were used as the antigen fraction in all cases. The total homogenate (fraction $\mathrm{H}$ ) and purified protein fraction (SODeCRU) at a concentration of 5 and $1.5 \mu \mathrm{g}$, respectively, was coated onto polystyrene microtitre plates (Nunc, Denmark) in carbonate buffer $(\mathrm{pH} 8.2)$ for $2 \mathrm{~h}$ at $37^{\circ} \mathrm{C}$. The antigen remaining on the plate was eliminated by washing three times with PBS-Tween 20 0.05\% (washing buffer). Free adsorption sites were taken by incubation ( $2 \mathrm{~h}$ at $37^{\circ} \mathrm{C}$ ) with blocking buffer (PBS-Tween $200.2 \%$, BSA $1 \%$ ). After being washed as described previously, the plates were incubated $\left(45 \mathrm{~min}\right.$ at $\left.37^{\circ} \mathrm{C}\right)$ with serum dilution of $1: 100$ in washing buffer. After a second washing, the plates were incubated in darkness for 20 min with $100 \mu \mathrm{L}$ of an enzymeconjugated antibody (Anti-IgG human peroxidase, Sigma) at a dilution of $1: 1000$. The enzyme reaction was developed with the chromogenic substrate OPD (o-Phenylenediamine dihydrochloride, Sigma) and $10 \mu \mathrm{L}$ of $30 \% \mathrm{H}_{2} \mathrm{O}_{2}$ per $25 \mathrm{~mL}$ for $20 \mathrm{~min}$ in the dark. The reaction was stopped by addition of $50 \mu \mathrm{L}$ of $\mathrm{HCl} 3 \mathrm{~N}$. Absorbance was read at $492 \mathrm{~nm}$ in a microplate reader (Sunrise, TECAN). All the samples were analysed in triplicate in polystyrene microtitre plates. Mean and standard deviations (SD) of the optical densities of the negative control sera (20 healthy humans) were used to calculate the cut-off value $($ mean $+3 \times \mathrm{SD})$ [12].

2.6. Western Blot Analysis. The antigen fraction of SODeCRU (at a concentration $1.5 \mu \mathrm{g}$ of protein) was run on IEF 39 gels and afterwards transferred to nitrocellulose membrane (Hybond C Extra, Amersham Pharmacia Biotech ) using the Phast-Transfer kit, as described by the manufacturer (PhastSystem handbook). The membrane was blocked for $2 \mathrm{~h}$ at room temperature using $0.4 \%$ gelatine and $0.2 \%$ Tween 20 in PBS, followed by three washes in $0.1 \%$ Tween 20 in PBS (PBS-T), and incubated for $2 \mathrm{~h}$ at room temperature, with donor sera at a dilution of $1 / 100$. Before being washed, the membrane was further incubated for $2 \mathrm{~h}$ at room temperature with the second antibody, anti-human immunoglobulin G (Fc specific) peroxidase conjugate (Sigma Immunochemical; dilution 1/1,000). After washing as above, the substrate diaminobenzidine $(0.5 \mathrm{mg} / \mathrm{mL}$ in buffer Tris/ $\mathrm{HCl} 0.1 \mathrm{M}, \mathrm{pH}$ 7.4, containing $1 / 5000 \mathrm{H}_{2} \mathrm{O}_{2}[10 \mathrm{v} / \mathrm{v}]$ ) was added and the reaction stopped with several washes in distilled water [12].

\section{Results and Discussion}

Due to the high incidence of Chagas disease in a vast variety of endemic areas and given the risk involved for humans as well as other species of mammals that act as natural reservoirs of T. cruzi, it is of utmost importance that the populations at high risk be provided with prevention measures. Everyday it becomes more necessary to develop a highly sensitive and specific diagnostic method to offer the adequate treatment in the least time possible to reduce the transmission of this parasitosis.

In this sense, the present study proposes the use of SODeCRU as a highly effective antigen to diagnose the infections by $T$. cruzi in human populations living in endemic zones of the disease. The different homogenate fractions $(\mathrm{H})$ and SODeCRU of T. cruzi obtained through the methodology described in Materials and Methods were tested by ELISA, against 258 human sera from suburban zones of the city of Santiago de Querétaro (Mexico). Of the total analysed, 8 sera proved positive against the $\mathrm{H}$ antigen fraction of T. cruzi (ELISA/(H)), for a prevalence of $3.0 \%$ (Figure 1).

For an evaluation of the antigenic potential of SODeCRU and its possible use in the immunodiagnosis of Chagas disease, these same sera were tested by the techniques of ELISA/SODeCRU and WB/SODeCRU. In this case, 31 proved positive against ELISA/SODeCRU from T. cruzi (for a prevalence of $12.0 \%$ ), while 30 sera were positive for $\mathrm{WB} / \mathrm{SODeCRU}$ (prevalence of 11.6\%) (Figure 1).

The agreement between the results for ELISA/SODeCRU and WB/SODeCRU was almost $100 \%$, with only the sera 49 and 157 showing positive with ELISA/SODeCRU but negative for WB/Fe-SODe, and, conversely, serum 226 gave a positive with $\mathrm{WB} / \mathrm{SODeCRU}$ but negative with ELISA/SODeCRU (Figures 2 and 3). This minor discrepancy indicated that the ELISA/SODeCRU can give false positives, whereas the WB detects lower antigen concentrations. However, the ELISA/SODeCRU continued to present high sensitivity and specificity. In addition, due to the low cost with respect to the WB, it can be considered a more adequate tool to use in rural endemic areas, where an adequate health system is not available to provide the equipment necessary to run the high-cost diagnostic tests [16].

Also, the presence of false positives in the ELISA technique may be due to cross reactions with other protozoa, fundamentally with Trypanosoma rangeli and with species belonging to the species belonging to the genus Leishmania, among others. This is a serious drawback in patients from geographical areas harbouring other infectious agents. However, in previous works, we have demonstrated that $\mathrm{Fe}$ SODe is species specific and thus does not present cross reactions with other trypanosomatids [12, 14, 17].

The main challenge that health workers face when undertaking an epidemiological study of Chagas disease is the choice of the diagnostic method. Numerous authors support the choice of serological tests $[11,18,19]$, while others suggest that serological methods are adequate only when combined with additional ones, this implying the use of two different techniques to be compared [20]. 
All parasitic protozoa investigated to data have been found to possess superoxide dismutase (SOD) linked to iron $(\mathrm{Fe})$, this enzyme being considered a virulence factor, permitting the invading parasites to survive the oxidant offensive activated by the host [21]. In addition, studies made with parasites belonging to the family Trypanosomatidae have corroborated the presence of this Fe-SODe [17, 22]. The differences between the protozoan Fe-SODe and those of the hosts, together with the immunogenic properties, make this Fe-SODe useful as a feasible molecular marker for the development of new diagnostic methods, in addition to potential therapeutic targets for designing new anti-Chagas drugs with the potential of taking advantage of the structural differences between Fe-SOD protozoans and the copperzinc-SOD of most eukaryotes [22].

Evaluating the results and taking into account the total of the human sera analysed with the ELISA/SODeCRU technique and comparing it to the technique of WB/SODeCRU as golden standard test, we found that the sensitivity of this technique reached $93 \%$, with specificity of $99 \%$ (Table 2). The predictive value for positives with the ELISA/SODeCRU technique was $93 \%$, and the predictive value for negatives was $99 \%$. The Kappa $(k)$ index of 1 confirmed that the proportion of agreement was total beyond random, between both assays ELISA/SODeCRU and WB/SODeCRU.

In general, because of the few cases documented parasitologically, Chagas disease is thought to be uncommon in Mexico, although it is probable that, like other diseases, cases are underrecorded for the lack of adequate diagnosis. The cases reported in the country correspond to the states of de Oaxaca, Chiapas, Jalisco, Michoacán, Guerrero, Zacatecas, Yucatán, Veracruz, Federal District of México, Sonora, and San Luis Potosí $[23,24]$. The prevalence reported is extremely varied, the data going from $2.8 \%$ for the state of Nuevo León, to $16.8 \%$ reported for the state of Veracruz $[25,26]$. In the state of Querétaro, the prevalence of this disease is unknown and data are available only for the year 2005 [17], when a prevalence of $8.6 \%$ was found in the rural population. For this reason, the second objective of the present study was to provide new epidemiological data on the disease in this state of Mexico, focusing on the suburban areas of the capital of this state.

The prevalence found in the present study is significantly greater than that reported in 2005. This could be due to a transfer of the disease from the rural setting to the urban one, and, on the other hand, it could be due to an increase in the disease. Prevalence in males was higher than in females $(17.0 \%$ versus $11.2 \%$, resp.) (Figure 4$)$, in agreement with findings reported by other authors [27], although, in some cases [28], the differences are not so significant. These discrepancies might be the result of cultural, behavioural, and socioeconomic differences among regions. The prevalence by ages shows that the group of persons between 36 and 50 years presented the highest prevalence (15.9\%; Figure 5). The individuals that tested positive in our study presented analytical alterations, some of them compatible with the chronic phase of the disease.

Some $35 \%$ of the patients presented some type of dyslipidaemia (DSP), diabetes mellitus types I and II, acute kidney failure followed by chronic heart failure, the latter reaching $29 \%$ of the interviewees, who presented high values of cardiac enzymes (CK-MB; Figure 6).

It was demonstrated that Fe-SOD excreted by T. cruzi was highly immunogenic and of high specificity, making it useful to diagnose Chagas disease at the same time as it provided epidemiological data on the seroprevalence of this disease in the suburban population of Santiago de Querétaro, formerly unstudied. These preliminary data reveal the degree of infection of nonrural areas of Mexico.

\section{Acknowledgments}

This work was supported by the University of Granada (Program GREIB, GREIB.PYR_2011_18). The authors are also grateful to Encarnación Guerrero for technical help in culture media preparation and David Nesbitt in the English revision.

\section{References}

[1] O. Gutiérrez-Sotelo, S. Molina-Solís, N. Calvo-Fonseca, L. Romero-Triana, L. Esquivel-Alfaro, and E. Campos, "Enfermedad de Chagas en pacientes con miocardiopatía dilatada idiopática en Costa Rica," Acta Medica, vol. 49, pp. 2-8, 2007.

[2] OPS/WHO/NTD/ID, "Estimación cuantitativa de la enfermedad de Chagas en las Américas," Organización Panamericana de la Salud, Washington DC, USA, OP5/HDM/CD/4250G, 2006.

[3] Y. Carlier, A. O. Luquetti, J. C. P. Dias, C. Truyens, and L. Kirchhoff, Chagas Disease (American Trypanosomiasis), 2003, http://www.emedicine.com/med/topic327.htm.

[4] Center for Food Security \& Public Health/Institute for International Cooperation in Animal Biologics, American Trypanosomiasis, CHAG_H2009S.es10, 2009.

[5] A. O. Luquetti, "Diagnóstico de la enfermedad de Chagas," in Enfermedad de Chagas, Sociedad Colombiana de Cardiología y Cirugía Vascular, F. Rosas, D. Vanegas, and M. Cabrales, Eds., pp. 25-32, Bogota, Colombia, 2007.

[6] W. Barbabosa, A. C. Czerewuta, and R. L. Oliveira, "Tentativa de isolamento primario de pacientes cronicos de doenca de Chagas por hemocultura agentes bloqueadores," Revista Patologia Tropical, vol. 12, pp. 155-163, 1983.

[7] L. M. P. Luz, M. G. Coutinho, J. R. Cancado, and A. U. Krettli, "Hemocultura: tecnica sensivel na deteccao do Trypanosoma cruzi em pacientes chagasicos na fase cronica da doenca de Chagas," Revista da Sociedade Brasileira de Medicina Tropical, vol. 27, pp. 143-148, 1994.

[8] P. Wincker, C. Britto, J. B. Pereira, M. A. Cardoso, W. Oelemann, and C. M. Morel, "Use of a simplified polymerase chain reaction procedure to detect Trypanosoma cruzi in blood samples from chronic chagasic patients in a rural endemic area," The American Journal of Tropical Medicine and Hygiene, vol. 51, no. 6, pp. 771-777, 1994.

[9] A. A. Portela-Lindoso and M. A. Shikanai-Yasuda, "Chronic Chagas' disease: from xenodiagnosis and hemoculture to polymerase chain reaction," Revista de Saude Publica, vol. 37, no. 1, pp. 107-115, 2003.

[10] WHO, Control de la Enfermedad de Chagas, Organización Mundial de la Salud, Ginebra, Switzerland, 2003.

[11] Z. C. Caballero, O. E. Sousa, W. P. Marques, A. Saez-Alquezar, and E. S. Umezawa, "Evaluation of serological tests to identify 
Trypanosoma cruzi infection in humans and determine crossreactivity with Trypanosoma rangeli and Leishmania spp.", Clinical and Vaccine Immunology, vol. 14, no. 8, pp. 10451049, 2007.

[12] C. Marín, S. S. Longoni, J. Urbano et al., "Enzyme-linked immunosorbent assay for superoxide dismutase-excreted antigen in diagnosis of sylvatic and andean cutaneous leishmaniasis of Peru," The American Journal of Tropical Medicine and Hygiene, vol. 80, no. 1, pp. 55-60, 2009.

[13] C. Marín and M. Sánchez-Moreno, "Excreted/secreted antigens in the diagnosis of Chagas' disease," in Immune Response to Parasitic Infections Vol.1, E. Jirillo and O. Brandonisio, Eds., pp. 10-20, Bentham Science Publishers E-book, 2010.

[14] S. S. Longoni, C. Marín, C. H. Sauri-Arceo et al., "An ironsuperoxide dismutase antigen-based serological screening of dogs indicates their potential role in the transmission of Cutaneous Leishmaniasis and Trypanosomiasis in Yucatan, Mexico," Vector-Borne and Zoonotic Diseases, vol. 11, pp. 815$821,2011$.

[15] W. F. Beyer and I. Fridovich, "Assaying for superoxide dismutase activity: some large consequences of minor changes in conditions," Analytical Biochemistry, vol. 161, no. 2, pp. 559566, 1987.

[16] C. Marín, S. S. Longoni, H. Mateo et al., "The use of an excreted superoxide dismutase in an ELISA and Western blotting for the diagnosis of Leishmania (Leishmania) infantum naturally infected dogs," Parasitology Research, vol. 101, no. 3, pp. 801-808, 2007.

[17] M. E. Villagrán, M. Sánchez-Moreno, C. Marín, M. Uribe, J. J. de la Cruz, and J. A. de Diego, "Seroprevalence to Trypanosoma cruzi in rural communities of the state of Querétaro (Mexico). Statistical evaluation of tests," Clinical Biochemistry, vol. 42, no. 1-2, pp. 12-16, 2009.

[18] E. A. Castro, V. Thomaz-Soccol, C. Augur, and E. Luz, "Leishmania (Viannia) braziliensis: epidemiology of canine cutaneous leishmaniasis in the State of Paraná (Brazil)," Experimental Parasitology, vol. 117, no. 1, pp. 13-21, 2007.

[19] M. Jiménez-Coello, E. Guzmán-Marín, A. Ortega-Pacheco, and K. Y. Acosta-Viana, "Serological survey of American trypanosomiasis in dogs and their owners from an urban area of Mérida Yucatàn, México," Transboundary and Emerging Diseases, vol. 57, no. 1-2, pp. 33-36, 2010.

[20] D. Otranto, F. Dantas-Torres, and E. B. Breitschwerdt, "Managing canine vector-borne diseases of zoonotic concern: part one," Trends in Parasitology, vol. 25, no. 5, pp. 228-235, 2009.

[21] W. J. Paramchuk, S. O. Ismail, A. Bhatia, and L. Gedamu, "Cloning, characterization and overexpression of two iron superoxide dismutase cDNAs from Leishmania chagasi: role in pathogenesis," Molecular and Biochemical Parasitology, vol. 90, no. 1, pp. 203-221, 1997.

[22] H. Mateo, C. Marín, G. Pérez-Cordón, and M. SánchezMoreno, "Purification and biochemical characterization of four iron superoxide dismutases in Trypanosoma cruzi," Memorias do Instituto Oswaldo Cruz, vol. 103, no. 3, pp. 271276, 2008 .

[23] J. M. Ramsey, A. Cruz-Celis, L. Salgado et al., "Efficacy of pyrethroid insecticides against domestic and peridomestic populations of Triatoma pallidipennis and Triatoma barberi (Reduviidae:Triatominae) vectors of Chagas' disease in Mexico," Journal of Medical Entomology, vol. 40, no. 6, pp. 912-920, 2003.

[24] P. M. Salazar Schettino, M. Bucio Torres, M. Cabrera Bravo, and A. L. Ruiz Hernández, "Presentación de dos casos de enfermedad de Chagas aguda en México," Gaceta Médica de México, vol. 147, no. 1, pp. 63-69, 2011.

[25] A. Ramos-Ligonio, A. López-Monteon, D. Guzmán-Gómez, J. L. Rosales-Encina, Y. Limón-Flores, and E. Dumonteil, "Identification of a hyperendemic area for Trypanosoma cruzi infection in central Veracruz, Mexico," The American Journal of Tropical Medicine and Hygiene, vol. 83, no. 1, pp. 164-170, 2010.

[26] L. Galavíz-Silva, D. P. Molina-Garza, M. A. González-Santos et al., "Update on seroprevalence of anti-Trypanosoma cruzi antibodies among blood donors in northeast Mexico," The American Journal of Tropical Medicine and Hygiene, vol. 81, no. 3, pp. 404-406, 2009.

[27] F. Sosa-Jurado, M. Mazariego-Aranda, N. Hernández-Becerril et al., "Electrocardiographic findings in Mexican chagasic subjects living in high and low endemic regions of Trypanosoma cruzi infection," Memorias do Instituto Oswaldo Cruz, vol. 98, no. 5, pp. 605-610, 2003.

[28] S. Juarez-Tobias, G. Vaughan, A. Torres-Montoya, and A. Escobar-Gutierrez, "Seroprevalence of Trypanosoma cruzi among Teenek Amerindian residents of the huasteca region in San Luis Potosi, Mexico," The American Journal of Tropical Medicine and Hygiene, vol. 81, no. 2, pp. 219-222, 2009. 

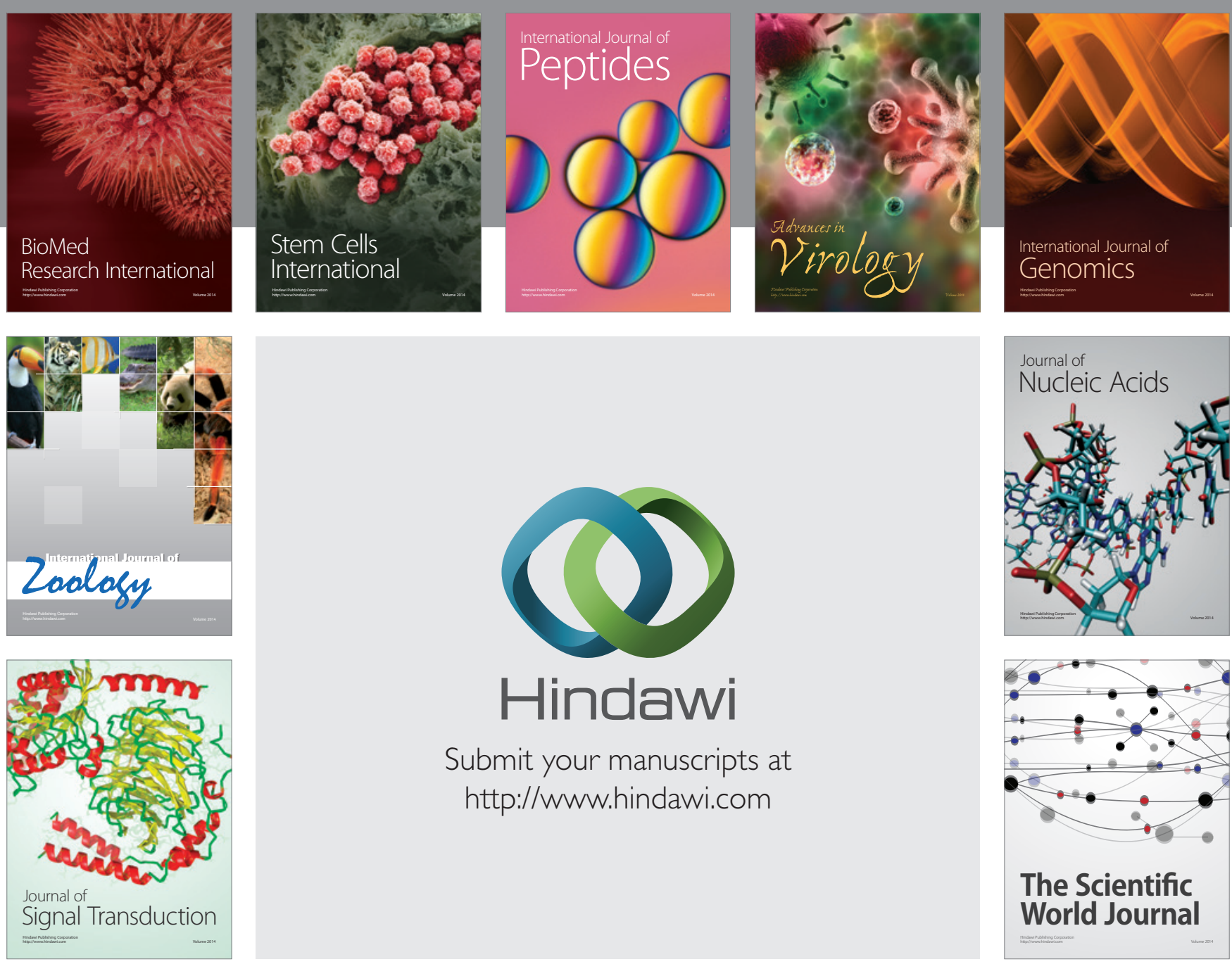

Submit your manuscripts at

http://www.hindawi.com
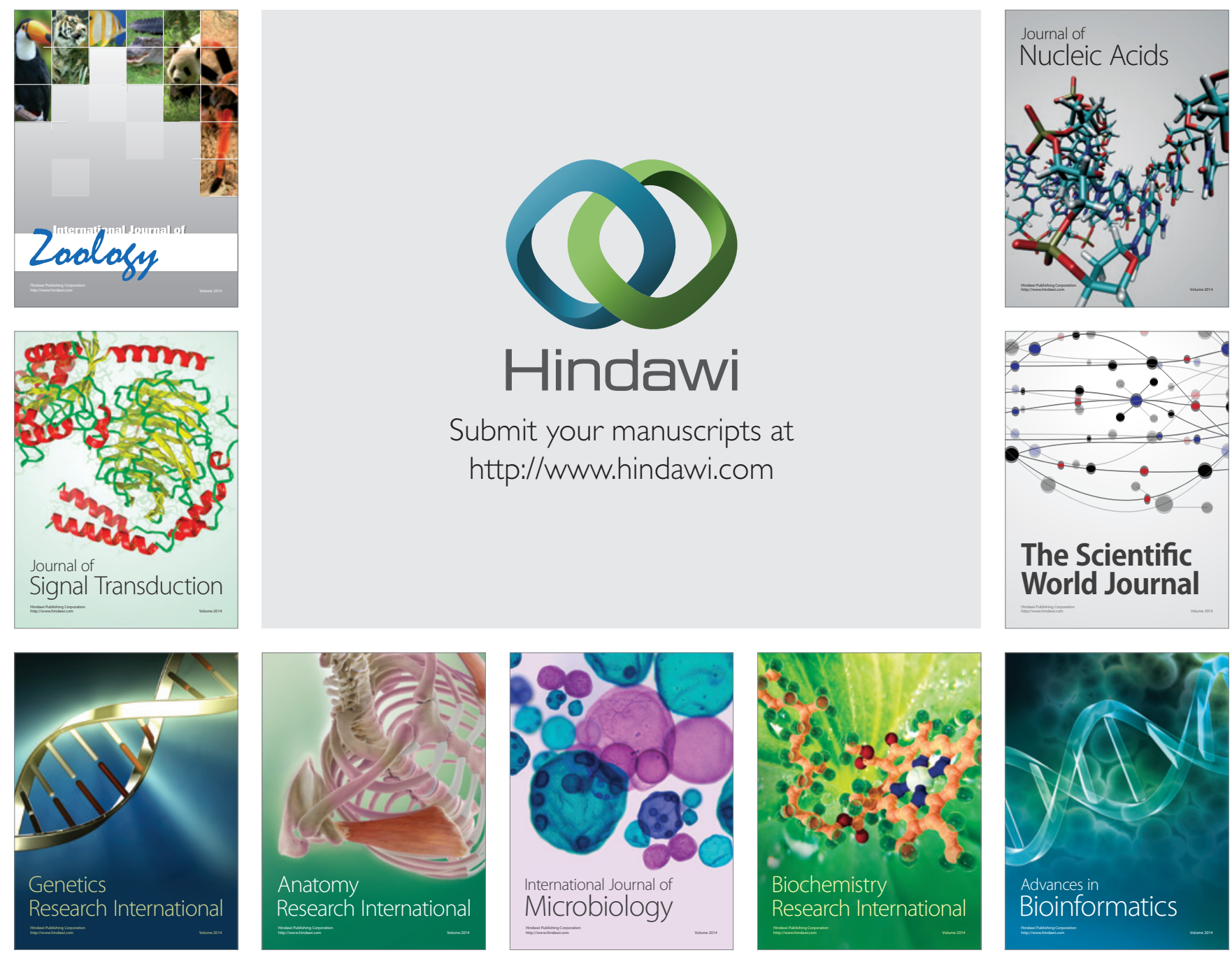

The Scientific World Journal
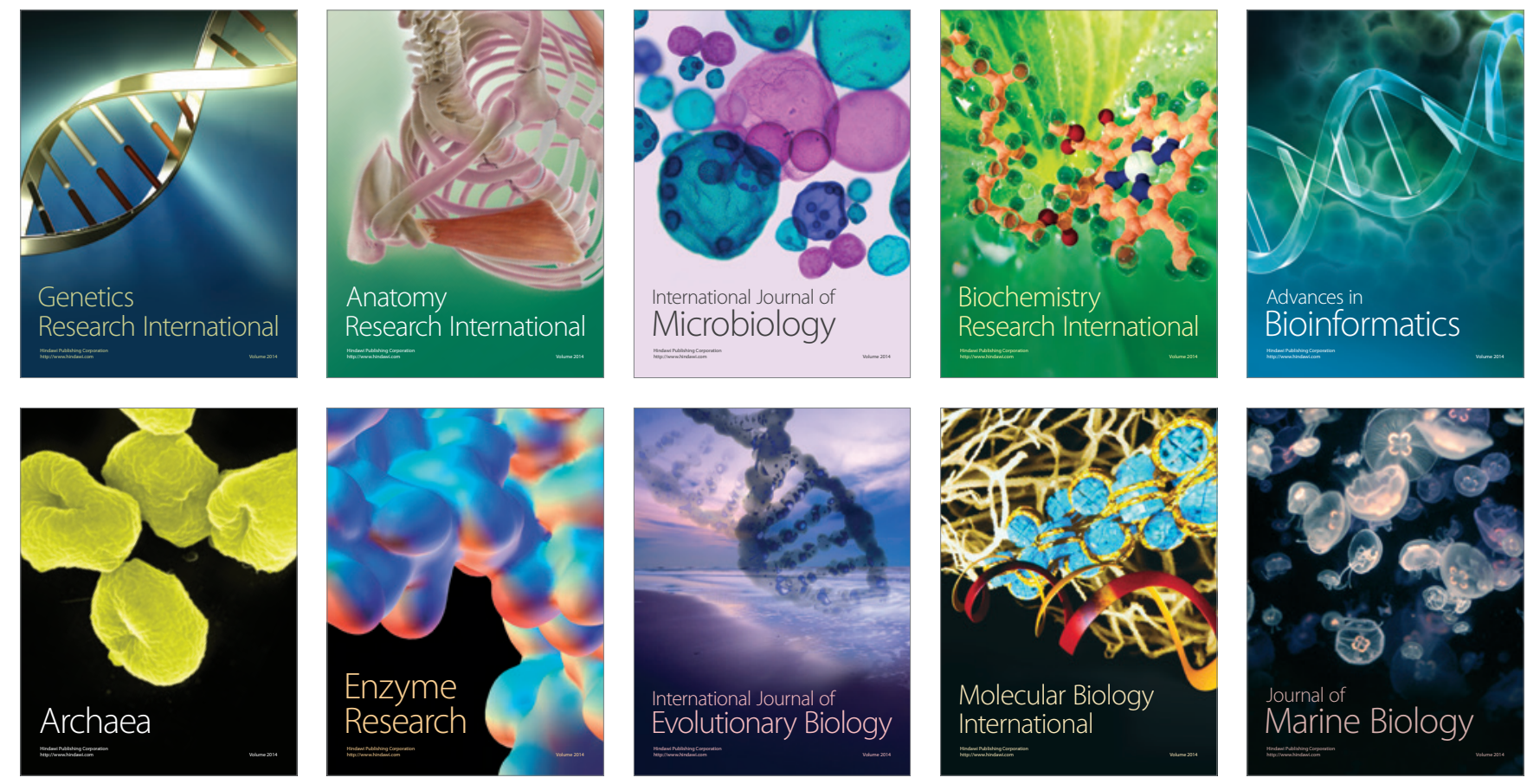